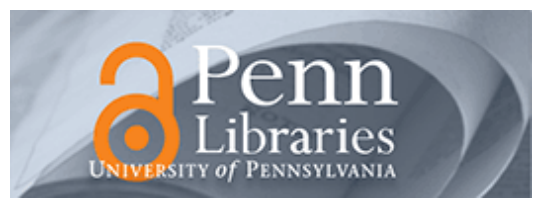

University of Pennsylvania

ScholarlyCommons

Management Papers

Wharton Faculty Research

$7-2013$

Persistence of Integration in the Face of Specialization: How Firms Navigated the Winds of Disintegration and Shaped the Architecture of the Semiconductor Industry

Rahul Kapoor

University of Pennsylvania

Follow this and additional works at: https://repository.upenn.edu/mgmt_papers

Part of the Business Administration, Management, and Operations Commons

Recommended Citation

Kapoor, R. (2013). Persistence of Integration in the Face of Specialization: How Firms Navigated the Winds of Disintegration and Shaped the Architecture of the Semiconductor Industry. Organization Science, 24 (4), 1195-1213. http://dx.doi.org/10.1287/orsc.1120.0802

This paper is posted at ScholarlyCommons. https://repository.upenn.edu/mgmt_papers/119

For more information, please contact repository@pobox.upenn.edu. 


\title{
Persistence of Integration in the Face of Specialization: How Firms Navigated the Winds of Disintegration and Shaped the Architecture of the Semiconductor Industry
}

\author{
Abstract \\ Although the stylized model of industry evolution suggests that firms transform from vertical integration \\ to specialization over time, many industries still exhibit a continued persistence of integrated firms. In \\ exploring this puzzle, I draw on detailed firm-level data from the semiconductor industry to analyze how \\ integrated incumbents, beyond shifting to the specialized mode, reconfigured in the face of industry's \\ vertical disintegration so as to coexist with the specialized firms. I propose and find that the incumbents \\ who persist with vertical integration increase their emphasis on systemic innovations and transact with \\ specialized firms in both upstream and intermediate markets. The value-creating opportunities \\ associated with integrated incumbents' leveraging (a) their relative superiority in developing systemic \\ innovations and (b) markets to pursue a broader menu of transactional choices may offset their costs of \\ staying integrated. These firm-level factors also determine the pattern of industry's vertical disintegration \\ and the extent of coexistence between integrated and specialized firms.

\section{Keywords} \\ firm boundaries, vertical integration, industry evolution, organizational adaptation, semiconductor industry \\ Disciplines \\ Business Administration, Management, and Operations
}




\title{
Persistence of Integration in the Face of Specialization: How Firms Navigated the Winds of Disintegration and Shaped the Architecture of the Semiconductor Industry
}

\author{
Rahul Kapoor \\ The Wharton School \\ University of Pennsylvania \\ Philadelphia, PA-19104 \\ Tel : 12158986458 \\ Email: kapoorr@wharton.upenn.edu
}

September 9, 2011

\begin{abstract}
A stylized model of industry evolution suggests that an industry is initially dominated by vertically integrated firms and over time, it transforms into a vertically specialized structure. Many industries, however, are characterized by a continued persistence of integrated firms despite a trend towards disintegration. In exploring this puzzle, I draw on detailed firm-level data from the semiconductor industry to analyze the response of integrated incumbents as the industry transitions towards greater specialization. I find a significant shift in the incumbents' capability development process following the emergence of specialized entrants as they seek to capitalize on their relative superiority in developing systemic innovations. Moreover, this shift occurs in parallel with an increase in transactions linking integrated incumbents with specialized firms in upstream and intermediate markets suggesting a source of potential complementarity between the two organizational forms. The findings argue that as an industry transitions from an integrated to a specialized structure, it presents new value creating opportunities for integrated incumbents that entail reconfiguration of their transactional environment and pursuing differentiated capability development processes. The extent to which these opportunities offset firms' costs of staying integrated will determine the pattern of industry's disintegration and the extent of co-existence between integrated and specialized firms.
\end{abstract}

I thank Rajshree Agarwal, Nick Argyres, Carliss Baldwin, Olivier Chatain, Anil Gupta, Steven Klepper, Dan Levinthal and the participants at the 2011 Smith Entrepreneurship Conference and the Bowman Seminar at the Wharton School for helpful reactions. I would like to acknowledge the financial support from the Global Initiatives Research Program and Mack Center for Technological Innovation at The Wharton School. I am grateful to Anindya Ghosh, Oluwemimo Oladapo and Yingnan Xu for their help in compiling some of the data used in the study. All errors are mine. 


\section{Introduction}

The link between industry evolution and vertical integration has long been of interest to scholars in economics and management. A stylized pattern that scholars have sought to explain is that an industry is initially dominated by vertically integrated firms. Over time, it transforms into a vertically specialized structure with new entrants that specialize in a specific stage of production entering the industry and with integrated incumbents either exiting or conforming to the specialized mode. The literature has uncovered a variety of mechanisms to explain the shift from integration to specialization. These include returns to scale due to market size (Stigler, 1951), reduction in transportation and communication costs (Chandler, 1990; Lamoreaux et al., 2003), increase in product and process modularity (Baldwin and Clark, 2000; Schilling, 2000; Langlois, 2003) and differences in capabilities and transaction costs along the value chain (Jacobides and Winter, 2005).

While valuable insights have been generated regarding the link between industry evolution and vertical integration, the exploration of this stylized pattern seems to have been carried out with an implicit assumption that integrated and specialized forms are substitute organizational forms in the context of an industry's evolution such that the rise of one corresponds to the demise of the other. Consistent with this view, scholars have provided empirical evidence from a number of industries showing that integrated incumbents either conform to the specialized mode as industry matures or risk inferior performance and industry failure (e.g., Langlois, 1992; Langlois and Robertson, 1992; Christensen, 1993; Fine, 1998; Jacobides, 2005). Many industries, however, are characterized by a continued persistence of integrated firms despite a trend towards vertical specialization (e.g., Argyres and Bigelow, 2010; Helfat and Campo-Rembado, 2010; Kapoor and Adner, 2011; Qian, Agarwal and Hoetker, 2011). Hence, while the stylized pattern of the shift from integration to specialization over the 
industry's life cycle appears to hold across numerous contexts, there seems to be significant variance across industries in the extent of this shift.

In this study, I explore the possible sources of this variance by examining how integrated incumbents, beyond conforming to the specialized form, may adapt in the face of industry's disintegration and continue to co-exist with the specialized firms. My examination is based on a broader menu of capabilities and transactional choices than what has been analyzed in the extant literature on industry evolution and vertical integration. I consider that integrated and specialized firms may differ in their capabilities to develop systemic innovations that entail extensive coordination and communication across different stages of production (Teece, 1988; 1996; Colfer and Baldwin, 2010). ${ }^{1}$ Such "integrative capabilities" are distinct from the stagespecific capabilities that enable firms to carry out individual stages of production and that have been emphasized in studies of vertical integration (cf. Helfat and Raubitschek, 2000; Helfat and Campo-Rembado, 2010; Qian et al., 2011). I also consider the possibility that integrated firms can gain supply-side efficiencies by leveraging the markets as the industry becomes more specialized. Such transactional menu expands the traditionally viewed firm boundary choice of make or buy to also include make-and-buy, and participation in intermediate markets by selling to specialized firms (Harrigan, 1984; Jacobides and Billinger, 2006; Parmigiani, 2007; Luo et al., 2011).

I carry out my examination in the context of the global semiconductor industry. Since the 1980s, the industry has been subjected to the process of vertical disintegration because of the entry of specialized "fabless" firms who design and sell semiconductor chips but unlike

\footnotetext{
${ }^{1}$ In this study, I draw on Teece's typology $(1988 ; 1996)$ to distinguish between autonomous and systemic innovation. I do this to be consistent with the literature that this study most closely draws from. As discussed by Wolter and Veloso (2008), Teece's typology can be overlaid on Henderson and Clark's typology (1990) such that systemic innovation can entail both architectural and radical innovation, and autonomous innovation can entail both incremental and modular innovation.
} 
integrated incumbents, rely on external suppliers for manufacturing (e.g., Macher, Mowery and Hodges, 1998; Hall and Ziedonis, 2001; Strojvas, 2005). Despite a significant rise in the number of specialized firms, a vast majority of integrated incumbents have continued to persist for over two decades without conforming to the specialized mode of organization. I draw on detailed firm-level data to analyze the response of integrated incumbents as the industry transitions towards greater specialization. I find a significant shift in the capability development process of integrated firms (i.e. the extent to which they develop a given type of capability) following the emergence of specialized firms so as to differentiate based on their relative superiority in developing systemic innovations. I also find a significant shift in their boundaries so as to create value from transacting with specialized firms in both upstream and intermediate markets while maintaining an integrated form.

The findings, while specific to a single industry, argue for a simple yet generalizable theoretical framework to explain the pattern of an industry's vertical disintegration. It suggests that as an industry transitions from an integrated to a specialized structure, there is a change in the distribution of capabilities among industry participants. This change presents new value creating opportunities for integrated incumbents that entail reshaping of their transactional environment and pursuing differentiated capability development. The extent to which these opportunities offset firms' costs of staying integrated will determine the pattern of industry's vertical disintegration and the extent of co-existence between integrated and specialized firms.

In the next section, I provide a brief overview of the literature on industry evolution and vertical integration. I conclude this section by identifying some of the gaps in the literature that this study seeks to address. I then present a detailed account of the vertical disintegration of the global semiconductor industry, and how integrated incumbents have responded to shifts in the 
industry's vertical structure. Finally, I discuss how the findings from the semiconductor industry help generate a theoretical framework that considers a broader menu of choices available to integrated firms, and explain the pattern of vertical integration as industry evolves.

\section{Industry Evolution and Vertical Integration}

The ubiquitous shifting of an industry's vertical structure over its life cycle has been an important line of inquiry for scholars in economics and management. The most noticeable early effort included Stigler's (1951) proposition that industries will be initially populated by vertically integrated firms. As the demand for the new product grows, it becomes profitable for specialized firms to carry out functions that exhibit increasing returns to scale (Smith, 1776). This pattern will eventually reverse during the declining stage of the industry when the smaller size of the market will make it inefficient for activities to be carried out by specialized firms. While the validity of Stigler's theory has been questioned on a number of grounds (e.g., Chandler, 1977; Williamson, 1985; Langlois and Robertson, 1995; Klepper, 1997; Bresnahan and Gambardella, 1998), the evolutionary shift from vertical integration to specialization has been documented in a wide array of industries. These include textile (Gibb, 1950), machine tool (Rosenberg, 1963), commercial aircraft (Mowery and Rosenberg, 1982), personal computer (Baldwin and Clark, 2000), stereo (Langlois and Robertson, 1992), disk drive (Christensen, 1993), software (Steinmueller, 1996), chemicals (Arora and Gambardella, 1998) and mortgage banking (Jacobides, 2005).

In developing a better understanding of the mechanisms underlying an industry's vertical disintegration, scholars have identified a range of factors that are not necessarily mutually exclusive. Baldwin and Clark (2000), Schilling (2000) and Langlois (2003) attribute the vertical specialization of the industry to the modularization of products and processes so as to manage 
greater technological complexity and provide heterogeneous users with greater flexibility to mix and match modules. As products and processes get modularized, it makes it easier for activities to be coordinated via markets, and results in industries being populated by specialized firms. Lamoreaux et al. (2003) attribute vertical specialization to the reduction in transportation and communication costs allowing for specialized firms to coordinate activities through long-term relationships. Jacobides and Winter (2005) integrate arguments from evolutionary economics, transaction cost economics and resource based view to explain the evolution of an industry's vertical structure over its life cycle. Their framework considers inter-temporal shifts in the distribution of capabilities and transaction costs governed by industry-level selection processes and past firm-level choices. In so doing, they are able to not only explain the typical shift from vertical integration to disintegration (e.g. U.S. Mortgage banking industry) but also explain the shift from specialization to reintegration observed in some industries that is brought about by technology discontinuities (e.g. Swiss watch manufacturing).

A noticeable feature of this literature has been an explicit attention towards explaining the rise of the specialized form, and in some cases, a sequential shift between integrated and specialized forms. The theoretical explanations that are offered and the empirical examinations that are carried out suggest that a specific form of an organization (integrated or specialized) dominates at a specific stage in an industry's evolution (e.g., Langlois, 1992; Langlois and Robertson, 1992; Christensen, 1993; Jacobides, 2005). Hence, the literature has tended to link the evolutionary processes operating in a given industry with the corresponding dominance of a specific form of organization - integrated or specialized. This approach is problematic for at least three reasons. 
First, it is inconsistent with the fact that many industries are characterized by the coexistence of both vertically integrated and specialized firms over extended periods of time (Helfat and Campo-Rembado, 2010; Kapoor and Adner, 2011; Colfer and Baldwin, 2010; Argyres and Bigelow, 2010; Qian et al., 2011). Christensen et al. (2002) and Argyres and Bigelow (2010) have argued and provided evidence that integrated and specialized firms can coexist in the same industry by pursuing distinct competitive positions that focus on either low cost or product differentiation. A complementary explanation has been provided by Helfat and Campo-Rembado (2010) who distinguish between capabilities within each stage of production and integrative capabilities that are required to coordinate the different stages of production. They theorize that in industries characterized by successive technology life cycles, integrated incumbents may continue to co-exist with specialized firms in order to maintain their integrative capabilities for developing systemic innovations in future (Teece, 1988; 1996). ${ }^{2}$

Second, by suggesting that industries shift from integration to specialization, the literature has implicitly constrained the menu of transactional choices faced by firms to either make or buy. This is at odds with the evidence from a variety of industries that firms often pursue a broader menu of transactional choices than make or buy (Harrigan, 1985; Jacobides and Billinger, 2006; Parmigiani, 2007; Luo et al., 2011). For example, firms have been shown to pursue both make and buy so as to gain flexibility and manage industry volatility, improve their bargaining power over external suppliers, and leverage theirs and suppliers' differential capabilities. Beyond make and buy for a given transaction, the menu of choices available to integrated firms also entails participation in intermediate product markets by supplying an

\footnotetext{
${ }^{2}$ I note that while these studies have explicitly considered relative effectiveness of integrated and specialized firms with respect to different competitive positions or types of innovation, they have not explicitly considered or shown the different ways in which integrated firms can adapt as the industry shifts from an integrated to a specialized structure.
} 
upstream good or service to external buyers in addition to internal consumption. Greater demand for the upstream activity help firms realize economies of scale. It also helps firms mitigate organizational inefficiencies associated with the low-powered incentives of hierarchies and ensure that the upstream unit stays competitive. Jacobides and Billinger (2006) explore this broad menu of transactional choices through their case study of a major European apparel firm. They found that the focal firm, rather than considering a simple make or buy choice, successfully pursued a "permeable" vertical structure that encompassed using both internal and external suppliers as well as participating in both intermediate and final product markets. Recently, Luo et al. (2011) documented the existence of similar vertical permeable structures in the Japanese electronics industry.

Finally, by suggesting that incumbent integrated firms either conform to a specialized organizational mode as industry evolves or risk inferior performance, the literature on industry evolution overlooks one of the important tenets of the field of strategic management that sustainability of a firm's competitive advantage is dependent on its ability to adapt to changes in the industry in ways that builds on its distinctive strengths and capitalizes on new opportunities (Teece et al., 1997). By conforming to a specialized mode in the face of industry's disintegration will likely expend incumbents with competitive parity rather than provide them with a source of competitive advantage. Hence, beyond conformance, incumbents may pursue other strategic reconfigurations in the face of an industry's vertical disintegration that would allow them to leverage their existing resources and capabilities, and sustain their competitive advantage.

In summary, while great progress has been made in understanding the mechanisms that underlie the shift in the vertical structure of industries, the literature has predominantly emphasized the substitution of the integrated form by the specialized form. The fact that many 
industries are populated by both integrated and specialized firms over extended periods of time and that the firm's menu of transactional choices is significantly broader than the make or buy choice suggest that the extant literature has a fairly limited reach in explaining how firm strategies and industry evolution interact to shape industry's vertical structure.

In attempting to fill this gap, I explore the possibility that integrated incumbents may respond to shifts in the industry's vertical structure by reconfiguring their capability development process towards achieving greater differentiation from specialized competitors, and by reconfiguring their transactional environment in order to benefit from new opportunities presented by the emergence of markets for upstream and downstream activities.

My examination of firms' capability development process focuses on both stage-specific capabilities that allow firms to carry out a given stage of production and integrative capabilities that allow firms to coordinate the different stages of production (Helfat and Raubitschek; 2000; Helfat and Campo-Rembado, 2010). Integrative capabilities play an especially important role in the development of systemic innovations that entail interdependence across stages (Teece, 1988; 1996). For example, if design and manufacturing are two stages of production, a systemic innovation would entail coordinated (and most likely co-specialized) changes in both design and manufacturing stages while an autonomous innovation would entail isolated changes in either design or manufacturing. Helfat and Campo-Rembado (2010) provide evidence from a number of industries that vertically integrated firms have a competitive advantage in creating systemic innovations. Hence, while specialized firms may have superior stage-specific capabilities, integrated firms are likely to have superior integrative capabilities for coordinating the different stages of production. I explore these arguments in the context of the global semiconductor industry. 


\section{Data}

The data for the study was collected using a variety of archival sources. I first obtained a list of all publicly traded semiconductor firms that competed in the industry between 1990 and 2008 from the Global Semiconductor Alliance (GSA), a trade association responsible for the collection and dissemination of industry data. ${ }^{3}$ A useful feature of the GSA database is that it categorizes firms according to whether they are vertically integrated or specialized. I then retrieved information on these firms' patent grants, financial performance and manufacturing activities. The data on patent grants was obtained from Derwent World Patents Index database. There are several advantages of using Derwent for the purpose of this study. First, given the truly global nature of the semiconductor industry, Derwent provides a worldwide coverage of patent grants issued to semiconductor firms. Second, the database accounts for the fact that firms may seek patent protection for the same invention in multiple jurisdictions as well as may have subsequent revisions to the original patent. A single patent record in the database (labeled as patent family) often combines multiple patents related to the same invention. Third, Derwent has developed a proprietary patent technology classification system that enables for a more effective identification of patents based on the function or the application domain that the invention corresponds to (cf. Cockburn, Henderson and Stern, 2000; Ziedonis, 2004; Alcacer and Zhao, 2010). This allowed me to characterize patents by semiconductor design and manufacturing, and analyze differences among firm capabilities. The data on firms' financial performance was retrieved from COMPUSTAT. Finally, information on firms' manufacturing

\footnotetext{
${ }^{3}$ While there are many privately held fabless semiconductor start-ups, they represent a very small fraction (less than 1 percent) of the total industry revenue. Given the capital intensive nature of the semiconductor industry, firms, once they achieve a certain scale tend to get publicly listed.
} 
activities was obtained from the World Fab Watch database maintained by SEMI ${ }^{\mathrm{TM}}$ and supplemented by firms' annual reports and press releases.

\section{Vertical Disintegration in the Semiconductor Industry, 1980s-2008}

Semiconductor industry has its origins dating back to the 1950s. Since the 1980 s, the industry has undergone a process of vertical disintegration that is spurred by the entry of a large number of specialized "fabless" firms who design and sell semiconductor chips but unlike vertically integrated incumbents, rely on external suppliers for manufacturing (Monteverde, 1995; Macher, Mowery and Hodges, 1998; Hall and Ziedonis, 2001). The vertical disintegration of the semiconductor industry has been attributed to several supply-side and demand-side factors (cf. Macher and Mowery, 2004). First, significant increases in the demand for a variety of semiconductor products made specialization economically attractive as specialized firms could derive economies of scale from their investments in the individual stages of production (e.g., Stigler, 1951). Second, maintaining the trajectory of progress characterized by Moore's law required large recurring capital investments in $R \& D$ and manufacturing, thus raising the barriers to entry for firms pursuing integrated strategies. Third, the standardization of manufacturing processes based on complementary metal-oxide-semiconductor (CMOS) circuits facilitated the creation of markets for manufacturing, and enabled specialized manufacturing suppliers (foundries) to offer the same manufacturing process to a large number of fabless firms. Finally, improvements in electronic design automation (EDA) software further facilitated the decoupling of the design-manufacturing interface by allowing designers to incorporate detailed capabilities of the manufacturing process and to evaluate the performance of the semiconductor product prior to its manufacturing. 
Figure 1 depicts the trend in the annual number of fabless and integrated firms (also known as Integrated Device Manufacturers (IDMs)) that were active in the semiconductor industry from 1984 to 2008. It presents an interesting dichotomy regarding the industry's vertical structure. While the semiconductor industry has gone through a significant period of vertical disintegration driven by the entry of fabless firms, integrated incumbents have continued to persist and co-exist with the fabless entrants. Only a small minority of integrated incumbents switched from vertical integration to specialization and almost all of the integrated incumbents have continued to survive in the industry during this period. ${ }^{4}$ This is despite the fact that technology progress in the industry during this period has been achieved along the performance trajectory specified by Moore's law. Hence, the industry has not faced any technology discontinuities which may favor (re)integration (Afuah, 2001; Jacobides and Winter, 2005).

(Insert Figure 1 about here)

In assessing the performance difference between integrated and specialized firms, Table 1 provides a regression analysis of the effect of firm- and industry-specific factors on the firm's

\footnotetext{
${ }^{4}$ The firms that switched from integration to specialization included Ramtron in 1998, Zarlink Semiconductor and Xicor in 2001, Semtech in 2002, Applied Micro Circuits, California Micro Devices and Conexant Systems in 2003, Zilog in 2004, Avago Technologies in 2005 and LSI Corp. in 2006.
} 
Return on Invested Capital (ROIC) for the fifteen year period, 1993-2007. ${ }^{5}$ There is a significant effect of firm size, firm age, industry growth and country of origin on firm performance. However, the analysis fails to reject the null hypothesis of no significant difference in the performance between fabless and IDM firms. Strojvas (2005) conducted a similar analysis comparing the ROIC performance of the sample of integrated and fabless firms whose stock is listed on a major US stock exchange and found support for the financial viability of integrated firms during the 1994-2003 period.

(Insert Table 1 about here)

In summary, while the semiconductor industry has been subjected to the wave of disintegration that is characteristic of many established industries (e.g., Langlois, 1992; Christensen, 1993; Fine, 1998; Baldwin and Clark, 2000; Jacobides, 2005), integrated firms seem to have adapted in ways that have allowed them to co-exist with the specialized entrants. In order to identify the possible reasons for this observed co-existence of specialized and integrated firms in the semiconductor industry, I explore the strategic response of the integrated incumbents in the face of industry's vertical disintegration. My examination is guided by the literatures on capabilities and firm boundaries. Specifically, I focus on the firms' capability development process and on their transactional choices as the industry became more specialized.

\footnotetext{
${ }^{5}$ ROIC has been widely used as a measure of firm performance both by managers and by investors (Porter, 2008). It is particularly attractive in the case of the semiconductor industry as it not only accounts for the capital required to generate returns but also accounts for the differences in the capital structure and tax structures across firms and countries. I also experimented with the Return on Sales (ROS) measure and found no significant difference in the performance between IDM and Fabless firms. An alternative measure of performance that I would have preferred to use would be firm survival. However, there are some theoretical and empirical issues with the use of firm survival to compare the performance difference between IDM and fabless firms. First, exit barriers for fabless firms are significantly lower than that for IDM firms making the interpretation of findings from firm survival models problematic. Second, the difference in the exit rates between fabless and IDM firms could in part be due to competition within these organizational forms rather than between organizational forms especially as the industry witnessed a high rate of entry by fabless firms in early 1990s. Finally, there were very few exit events by IDM firms during the period of the study and most of those were driven by mergers or acquisitions.
} 


\section{$\underline{\text { Shift in the Capability Development Process }}$}

I assess whether the period of disintegration in the semiconductor industry was associated with changes in the capability development process of integrated incumbents. In particular, I analyze differences in the extent to which firms pursue autonomous vs. systemic innovations (Teece, 1988; 1996). While autonomous innovations are enabled by firms' capabilities for the specific stage of production (i.e., design or manufacturing), systemic innovations are enabled by firms' integrative capabilities that enable them to coordinate interdependent stages and create novel combinations of design and manufacturing (Helfat and Raubitschek, 2000; Helfat and Campo-Rembado, 2010; Qian et al., 2011). Differences in the extent to which firms develop autonomous and systemic innovations will likely correspond to the differences in the firms' stage-specific or integrative capabilities. For a given firm, a temporal shift in the extent to which it develops autonomous and systemic innovations signals a shift in the capability development process.

The analysis is carried out using information on firms' patent grants that are filed between 1993 and 2007. ${ }^{6}$ There are many caveats regarding the use of patents as an indicator of firms’ R\&D (e.g., Griliches, 1990; Cohen et al., 2000). Most notably, the propensity and motivation for firms to patent their innovations differs across industries. By focusing on a single industry and the one in which firms are known to have a very high propensity to patent (Hall and Ziedonis, 2001), I am able to somewhat mitigate this concern. In addition, the use of patent counts as a proxy for the economic value generated by a firm's R\&D efforts can also be problematic in certain contexts. In this study, I do not consider patent counts as an indicator of

\footnotetext{
${ }^{6}$ I chose to include patent grant data only up to 2007 because it takes on an average about two years for a patent application to be granted. Many of the patent applications that are filed in or after 2008 are unlikely to be granted by 2009 , the last year for which the data for the study was collected.
} 
firm performance. Rather, I consider changes in the share of firms' patents that correspond to autonomous and systemic innovations as a proxy for their capability development process. This approach is consistent with prior research that has used patent data to study firms' development of technological capabilities with a specific focus on the distribution of different types of capabilities (e.g., Argyres, 1996; Brusoni et al., 2001).

Each patent record in the Derwent database corresponds to a specific innovation by the firm and often includes multiple patent grants as a result of applications that are filed in different legal jurisdictions or filed as continuations of the original invention. I use the Derwent technology classification system to identify patents corresponding to semiconductor design or manufacturing. Derwent categorizes all patents in its database into 21 distinct technology sections, each one of which are divided into several classes. Section U titled Semiconductors and Electronic Circuitry is the primary section for all semiconductor related patents (e.g., Ziedonis, 2004). Many of the patents granted to semiconductor firms are also classified into sections T (Computing and Control), W (Communications) and L (Refractories, Ceramics, Cement and Electro(in)Organics). Together these four sections account for about $97 \%$ of fabless firms' patents and about $80 \%$ of IDM firms' patents. ${ }^{7}$

In order to categorize the technology classes into semiconductor design or manufacturing, I contacted four industry experts - two of whom have been associated with IDM firms, one with a fabless firm, and one from academia. Each of these experts has been active in semiconductor R\&D for more than fifteen years. I compiled a table that included a description of the four Derwent technology sections and all the classes within the four sections. I then circulated the table among the four experts and requested them to identify whether the description of the class

\footnotetext{
${ }^{7}$ The percentage of semiconductor related patents identified for IDM firms was lower than that for fabless firms as a number of IDM firms such as Hitachi and Toshiba are diversified conglomerates and hence, active in many different industries and technologies.
} 
refers to semiconductor design or manufacturing or possibly, both. Table 2 provides the list of the different Derwent classes and their categorization into either design or manufacturing based on the feedback received from the industry experts. ${ }^{8}$ I used this information to identify the extent to which firms pursue autonomous and systemic innovations (e.g. Teece, 1996; Helfat and Campo-Rembado, 2010). I consider a patented innovation as autonomous if it is categorized by either design-only or manufacturing-only classes. I consider a patented innovation as systemic if it is categorized by both design and manufacturing classes suggesting a strong coupling between the two distinct knowledge bases (e.g., Yayavaram and Ahuja, 2008).

(Insert Table 2 about here)

Figure 2 depicts the trend in the average share of firms' patents that correspond to autonomous and systemic innovations. It illustrates several important differences in the innovative behavior between fabless and IDM firms. Given that fabless firms specialize in semiconductor design, the dominant category of patented innovation for fabless firms is designbased autonomous innovation. These innovations typically represent more than $80 \%$ of the fabless firms' patents and this ratio is fairly stable over time. The small remainder tends to be shared between manufacturing-based autonomous innovations and systemic innovations. The fact that specialized design firms invest in manufacturing R\&D is consistent with the view that firms' knowledge boundaries tend to be broader than their production boundaries in order to manage the integration of external inputs or components during technology development (Brusoni et al., 2001; Kapoor and Adner, 2011).

\footnotetext{
${ }^{8}$ One expert commented that class U14 may correspond to both design and manufacturing activities. As a robustness check, I excluded all patents that were classified in this class and the findings were very similar to the ones reported in the paper.
} 
(Insert Figure 2 about here)

For IDM firms, the design-only innovation represents about $50 \%$ of all patents and this ratio seems on an average to be decreasing over time. The manufacturing-only innovation represents about $15 \%$ of all patents and this ratio exhibits an increasing trend from 1993 to 2000 followed by a slight decreasing trend from 2000 to 2007. The higher share of design patents as compared to manufacturing patents can in part be explained by the fact that a given manufacturing process can be used to commercialize many different product designs.

The share of systemic innovations for IDM firms is significantly greater than that for fabless firms. On an average, $17 \%$ of innovations for IDM firms are systemic whereas this ratio is only $6 \%$ for fabless firms. This evidence is consistent with the argument that vertical integration facilitates communication as well as coordination of tasks and investments that underlie systemic innovations (Teece, 1988; 1996, Monteverde, 1995; Strojvas, 2005; Helfat and Campo-Rembado, 2010; Kapoor and Adner, 2011). Industry executives from IDM firms often discuss how a tight coupling between design and manufacturing stages facilitates the development of systemic innovations and allows their firms to create a differentiation based advantage over fabless firms:

"It [vertical integration] allows us to develop a design and have the interaction we need with manufacturing. That synergy allows us to provide the best product for our customers." (Chekib Akrout, vice president of technology at Freescale Semiconductor quoted in EE Times 10/10/2006)

"if you're going to build a real SOC [an advanced semiconductor product that combines different types of functions on a single chip], you don't need only the basic process technology that you find in the foundries, you also need a lot of process variations that give you the differentiation you want. So your own manufacturing capability gives you a 
very strong competitive advantage with the ability to differentiate, and therefore add value, and therefore have a bigger margin." (Pasquale Pistorio, CEO of STMicroelectronics quoted in Electronic News 11/11/2002)

On an average, the percentage of systemic innovations for IDM firms exhibits an increasing trend moving from $9 \%$ in 1993 to $24 \%$ in 2007. The percentage of systemic innovations for IDM firms becomes especially high since the late 1990s whereas this percentage is low and relatively constant for the fabless firms. Note that the positive slope observed for integrated firms is steeper than the slope for all firms in the industry. This helps to rule out the possibility that the increase in the share of systemic innovations for integrated firms is due to exogenous changes in the technological opportunities in the industry.

(Insert Table 3 about here)

In order to verify that the trend in figure 2 with respect to systemic innovations is robust to unobserved firm-level differences, table 3 provides results from the firm fixed effects regression analysis. The dependent variable is the firms' share of patents that correspond to systemic innovations. The independent variables include dummies for each year from 1994 to 2007 and the share of firms' patents that relate to semiconductor design and manufacturing. Figure 3 plots the estimated coefficients and 95\% confidence intervals for each of the years from 1994 to 2007 included in the fixed effects model. The results from the fixed effects models are consistent with the trend observed in figure 2. The share of systemic innovations generated by IDM firms have been persistently increasing since the late 1990s whereas no such effect is observed for fabless firms. Hence, given that such innovations are an important driver of competitive advantage for integrated firms over specialized firms, IDM firms seem to have 
increased their emphasis on developing systemic innovations in order to differentiate from fabless firms.

(Insert Figure 3 about here)

In summary, the evidence from firms' patent grants in the semiconductor industry lends support to the argument that vertical integration facilitates the development of systemic innovation (Teece, 1996). More importantly, the analysis points to a significant shift in the capability development process of IDM firms since the late 1990s so as to capitalize on their superior superiority in developing systemic innovation. Whereas fabless firms were able to enter and compete in the industry without incurring substantial investments in manufacturing, IDM firms having incurred these investments in the past shifted their capability development efforts towards integrative capabilities so as to defend their competitive position against the rising tide of specialized firms.

\section{Reshaping of the Transactional Environment}

Earlier studies on industry evolution and vertical integration have shown that integrated firms, in the face of industry's disintegration, either conform to the new mode of organization by outsourcing various inputs or perish due to their inability to compete with their specialized rivals (Langlois, 1992; Christensen, 1993; Fine, 1998; Baldwin and Clark, 2000; Jacobides, 2005). The case of the semiconductor industry presents a very different scenario. Only a handful of IDM firms shifted to a fabless mode between 1990 and 2008. A vast majority of firms continued to have internal manufacturing. 
Instead of pursuing a more conventional make or buy choice, many firms leveraged the creation of markets to pursue a make-and-buy choice that entailed having their own in-house manufacturing as well as using external specialized foundry suppliers. Figure 4 plots the cumulative number of IDM firms that announced a shift in their manufacturing strategy from make to make-and-buy. It exhibits an increasing trend in the number of IDM firms using specialized foundries to carry out a proportion of their manufacturing.

\section{(Insert Figure 4 about here)}

This plural mode of internal and external sourcing allowed IDM firms flexibility with respect to their $\mathrm{R} \& \mathrm{D}$ and capacity investments especially during periods of high demand uncertainty (e.g., Harrigan, 1985; Parmigiani, 2007). ${ }^{9}$ For example, STMicroelectronics, one of the largest European-based semiconductor firms, discussed the benefit of this strategic shift in its 2003 annual report:

We have also developed relationships with outside contractors for foundry and back-end services. We view these relationships as giving us the flexibility when required by market demand to outsource up to a maximum of $20 \%$ of each of our front-end and back-end production requirements, enabling us to manage the supply chain to our customers without a commensurate increase in capital spending. (STMicroelectronics 2003 annual report).

In addition to gaining flexibility, the make-and-buy choice also enabled IDM firms to access external suppliers for certain types of manufacturing processes for which specialized foundries may be more efficient and to focus their internal efforts on manufacturing processes

\footnotetext{
${ }^{9}$ In some cases, the make-and-buy choice pursued by IDM firms also accompanied licensing of certain types of process technologies from IDMs to foundries.
} 
for which integrated firms may be more efficient. For example, Texas Instruments (TI), one of the largest US-based semiconductor firms, leveraged theirs and suppliers' differentiated capabilities by using a combination of external and internal manufacturing for digital processes while pursuing an internal-only route for analog processes. TI discussed the benefit of this strategy in its 2007 annual report:

TI benefited from its hybrid manufacturing model, with the company employing a combination of internal and third-party foundry manufacturing for advanced digital processes. This hybrid approach provided the company with more flexibility in its operations to adapt to changing market conditions yet focus its internal efforts more intently on analog. TI continued to enhance its analog capabilities, significantly increasing the number of researchers involved in analog process development while also expanding analog manufacturing capacity. (Texas Instruments 2007 annual report)

An alternative approach to evaluating the transactions between integrated firms and specialized foundries is presented in figure 4 that provides data from the "other" side of the transaction. It plots the percentage sales to IDM firms from 1998 to 2008 for the two largest specialized foundries - Taiwan Semiconductor Manufacturing Corporation (TSMC) and United Microelectronics Corporation (UMC). TSMC and UMC have jointly accounted for more than $60 \%$ of the worldwide foundry market share during this period. While the two foundries have exhibited dramatic growth, IDM firms have constituted an important market segment for these foundries and sales to IDM firms have represented, on an average, about $30 \%$ of their total annual sales. Hence, the data plotted in figure 5 is consistent with the make-and-buy industry trend observed in figure 4.

(Insert Figure 5 about here) 
Besides the opportunity of benefitting from the make-and-buy mode, the specialization of industry also presented integrated firms with an opportunity to participate in intermediate markets by offering their manufacturing services to fabless firms in addition to their own internal use. Figure 3 shows the trend in the number of IDM firms offering their manufacturing services to fabless firms. There has been a rapid rise in the number of IDM firms offering such services. In 1997, only 7 of the IDMs participated in the intermediate market for manufacturing whereas in 2008, this number grew to 39. This strategy had a direct benefit of providing integrated firms with additional demand for their manufacturing capabilities and helping economize on high fixed costs of R\&D and production. For example, IBM was one of the earliest of the integrated incumbents to have embraced this strategy and highlighted it as a key part of its transformation during the 1990s:

There was a time when all our component technologies, such as semiconductors and hard disk drives, went inside our own products. And only there. That was then, this is now. In order to support our massive investments in $R \& D$, we needed additional revenue streams, so we began doing something previously unthinkable - selling our technology products to other high-tech companies. Fortunately, our technology was so good that we sold a lot of it-multibillion dollars' worth.... In 2001, IBM was one of only two top-30 chip makers that grew revenue. (IBM 2001 annual report)

Besides creating greater demand for incumbents' manufacturing assets and capabilities, this strategy also helped reduce the dominance of specialized foundries by increasing competition in upstream markets. The benefit of having greater number of manufacturing suppliers was often a key part of the sales pitch by executives at IDM firms offering their manufacturing services to fabless firms (Morrison, 1998). Finally, by selling their manufacturing capacity to external customers, the corporate office mitigated the organizational 
inefficiencies associated with low-powered incentives of the hierarchies (Williamson, 1985), and helped ensure that the upstream manufacturing unit stays competitive.

In summary, the evidence regarding the reshaping of transactional environment by integrated incumbents shows how the emergence of specialized firms presented integrated incumbents with new corporate alternatives for creating value. These value creating opportunities were enabled by the presence of specialized firms. Participation in intermediate markets as manufacturing suppliers to fabless firms and the shift to make-and-buy mode of manufacturing allowed the integrated firms to leverage markets and gain supply-side efficiencies while retaining integrative capabilities to develop and commercialize systemic innovations.

Given the two different types of transactional reconfigurations pursued by integrated incumbents, an obvious issue to consider is the nature of variance among these firms. Integrated firms are likely to differ in their extent and the type of manufacturing that is outsourced and offered though intermediate markets. For example, whether and to what extent integrated firms participate in intermediate markets is likely to be a function of the specialized investments required to support customers in such markets as well as the appropriability hazards that firms may be subjected to by sharing their intellectual property with firms who may be current or potential competitors in the product market (Henkel and Baldwin, 2011; Luo et al., 2011). Similarly, the extent to which integrated firms use external manufacturing suppliers is likely to be shaped by the firms' and suppliers' scope economies, capabilities and technological uncertainty (Parmigiani, 2007).

I also note that such reconfiguration of transactional environment, while allowing for greater value creation for IDM firms, is not without its own set of organizational challenges. For example, it would require establishing new marketing and sales capabilities to support new types 
of customers as well as the development of procurement capabilities to manage relationships with external foundry suppliers. Perhaps more importantly, it would require that the corporate executives modify existing organizational designs and incentive structures in order for the internal product design and manufacturing units to support each other while maintaining relationships with external foundry suppliers and fabless customers. For example, Jacobides and Billinger's (2006) detailed account of the reconfiguration of firm boundaries at a major European apparel firm provide valuable insights on how such strategies required new organizational designs. These included changes in how information is managed within and across business units, the establishment of profit and loss centers for each business unit and changes in transfer pricing to a cost-plus model. The relative success of these transactional reconfigurations will likely be determined by the effectiveness with which IDM firms can manage the new transactional environment through changes in internal routines and capabilities.

\section{Discussion and Conclusion}

The literature on industry evolution and vertical integration has generated valuable insights regarding why industries shift from a vertically integrated to a specialized structure over time (Stigler, 1951; Baldwin and Clark, 2000; Lamoreaux et al., 2003; Jacobides, 2005). Many industries, however, are characterized by a continued persistence of integrated firms despite a trend towards vertical disintegration (Christensen et al., 2002; Argyres and Bigelow, 2010; Helfat and Campo-Rembado, 2010; Kapoor and Adner, 2011). In this study, I explore the underlying drivers of such persistence by considering how integrated incumbents may respond to shift in the industry's vertical structure by reconfiguring their capabilities and reshaping their boundaries in order to achieve a better fit with the new environment. 
I base my examination on a broader menu of capabilities and transactional choices than what has been analyzed in the literature on industry evolution and vertical integration. I consider stage-specific capabilities that enable firms to carry out individual stages of production (e.g., design or manufacturing) and also integrative capabilities that enable firms to coordinate the different stages of production (Helfat and Raubitschek; 2000; Helfat and Campo-Rembado, 2010; Qian et al., 2011). I consider the firm's menu of transactional choices to not only include the traditional make or buy choice but also include make-and-buy as well as participation in intermediate markets by selling to specialized firms (Harrigan, 1984; Jacobides and Billinger, 2006; Parmigiani, 2007; Luo et al., 2011).

The analysis is conducted in the context of the global semiconductor industry. Since the 1980s, the industry has transitioned from an integrated structure to a more specialized structure. The change in the industry structure was driven by the entry of specialized fabless firms who design and sell semiconductor products but rely on external suppliers for manufacturing. However, for over two decades, a vast majority of integrated incumbents have continued to persist and co-exist with the specialized firms. In uncovering the possible drivers of coexistence, I find a significant shift in the capability development process of integrated firms following the emergence of specialized firms so as to leverage their relative superiority in developing systemic innovations. I also find a significant shift in their boundaries so as to generate supply-side efficiencies from transacting with specialized firms in both upstream and intermediate markets while maintaining an integrated form.

Figure 6 summarizes the main findings from the study and notes the changes in the capability distribution, capability development and transactions among industry participants in the semiconductor industry over time. 
(Insert Figure 6 about here)

The evidence from the semiconductor industry helps generate a simple framework that explicitly considers capabilities for each stage of production as well as integrative capabilities to coordinate different stages of production. It suggests that as an industry transitions from an integrated to a specialized structure, there is a shift in the distribution of capabilities among industry participants. This shift presents new value creating opportunities to integrated firms that entail reconfiguration of their transactional environment and pursuing differentiated capability development so as capitalize on their relative superiority in developing systemic innovations. The extent to which firms' costs of staying integrated will be offset by the supply-side efficiency gains from transacting with specialized firms in upstream and intermediate markets, and the demand-side premium from systemic innovations will determine the pattern of industry's vertical disintegration and the nature of co-existence between integrated and specialized firms.

The framework supplements existing accounts of industry evolution and vertical integration which have predominantly focused on explaining the emergence and the eventual dominance of the specialized organizational form (e.g., Langlois, 1992; Christensen, 1993; Fine, 1998; Baldwin and Clark, 2000; Jacobides, 2005). In so doing, the extant literature has tended to either implicitly or explicitly assume that the rise of the specialized form corresponds to the demise of the integrated form. By considering differentiated capability development for integrated and specialized firms, and by allowing for transactions between integrated and specialized firms in both upstream and intermediate markets, the framework developed in the 
study gives a more prominent role to how integrated firms can adapt in the face of industry's vertical disintegration and co-exist with the specialized firms.

The framework and the supporting evidence from the semiconductor industry is also consistent with the formal model developed by Helfat and Campo-Rembado (2010) in which they show that the co-existence of vertically integrated and specialized firms in an industry would be characterized by integrated firms competing through systemic innovations in the same product market. While their model explicitly considered exogenous technology shifts in the industry leading to systemic innovations, the authors also discuss the possibility that integrated firms will be more likely to proactively develop and commercialize systemic innovations.

The study has a number of limitations and I hope that future research would address these shortcomings. First, the study is carried out in the context of a single industry and the generalizability of the findings and suggested framework would need to be established through exploration in other industries. Second, while the use of patent data allows me to examine the evolution of firm capabilities in the semiconductor industry, the measure is not applicable in all industries. Future work could explore other measures to assess differential capability development by integrated and specialized firms. Third, while I present some preliminary evidence on the performance of integrated and specialized firms, much more needs to be done to understand the sources of performance differences both between and within the two forms of organization. For example, I am unable to uncover the organizational challenges and inertia that integrated incumbents may face in reconfiguring their capabilities and exploiting opportunities in upstream and intermediate product markets. Also, the non-availability of data precludes me from examining the sources of heterogeneity among integrated firms with respect to the reshaping of their transactional environment. 
Despite these and other limitations, I hope that the study has provided an important step forward in our understanding of the interaction between vertical integration and industry evolution. In so doing, it has contributed to the broader agenda of explaining how firm strategies and industry evolution interact to shape industry structure. 


\section{References}

Afuah, A. 2001. Dynamic Boundaries of the Firm: Are Firms Better off Being Vertically Integrated in the Face of a Technological Change? Academy of Management Journal, 44(6): 1211-1228.

Alcacer, J., \& Zhao, M. 2010. Local R\&D Strategies and Multi-location Firms: The Role of Internal Linkages. Harvard Business School Working Paper, No. 10-064.

Argyres, N.S. 1996. Capabilities, Technological Diversification and Divisionalization. Strategic Management Journal, 17 395-410.

Argyres, N., \& Bigelow, L. 2010. Innovation, Modularity, and Vertical Deintegration: Evidence from the Early US Auto Industry. Organization Science, 21(4): 842-853.

Arora, A., \& Gambardella, A. 1998. Evolution of industry structure in the chemical industry. In A. Arora, R. Landau, \& N. Rosenberg (Eds.), Chemicals and Long-Term Economic Growth: 379-414. New York: Wiley.

Baldwin, C. Y., \& Clark, K. B. 2000. Design Rules. Volume 1: The Power of Modularity. Cambridge, MA: MIT Press.

Bresnahan, T., \& Gambardella, A. 1998. The division of inventive labor and the extent of the market. In E. Helpman (Ed.), General Purpose Technologies and Economic Growth, MIT Press, Cambridge MA: 253-282.

Brusoni, S., Prencipe, A., \& Pavitt, K. 2001. Knowledge Specialization, Organizational Coupling, and the Boundaries of the Firm: Why Do Firms Know More Than They Make? Administrative Science Quarterly, 46(4): 597-621.

Chandler, A. D. 1977. The Visible Hand. Boston: Belknap.

Chandler, A. D. 1990. Scale and scope: the dynamics of industrial capitalism. Cambridge, Mass.: Belknap Press.

Christensen, C. M. 1993. The Rigid Disk-Drive Industry - A History Of Commercial And Technological Turbulence. Business History Review, 67(4): 531-588.

Christensen, C. M., Verlinden, M., \& Westerman, G. 2002. Disruption, Disintegration, and the Dissipation of Differentiability. Industrial \& Corporate Change, 11(5): 955-993.

Cockburn, I. M., Henderson, R. M., \& Stern, S. 2000. Untangling the origins of competitive advantage. Strategic Management Journal, 21(10-11): 1123-1145.

Cohen, W. M., Nelson, R. R., \& Walsh, J. 2000. Protecting their intellectual assets: Appropriability conditions and why US manufacturing firms patent (or not): National Bureau of Economic Research Cambridge, Mass., USA.

Colfer, L., \& Baldwin, C. Y. 2010. The mirroring hypothesis: theory and evidence on the correspondence between the structure of products and organizations, Harvard Business School Working Paper.

Fine, C. H. 1998. Clockspeed: Winning industry control in the age of temporary advantage. Reading, MA: Perseus Books.

Gibb, G. S. 1950. The Saco-Lowell Shops: Textile Machinery Building in New England, 1813-1849: Cambridge, Mass., Harvard University Press.

Griliches, Z. 1990. Patent statistics as economic indicators. Journal of Economic Literature, 28(4): 16611707.

Hall, B. H., \& Ziedonis, R. H. 2001. The Patent Paradox Revisited: An Empirical Study of Patenting in the U.S. Semiconductor Industry, 1979-1995. RAND Journal of Economics, 32(1): 101-128.

Harrigan, K. 1984. Formulating vertical integration strategies. Academy of Management Review, 9(4): 638-652. 
Harrigan, K. R. 1985. Vertical integration and corporate strategy. Academy of Management Journal, 28(2): 397-425.

Helfat, C. E., \& Raubitschek, R. S. 2000. Product sequencing: Co-evolution of knowledge, capabilities and products. Strategic Management Journal, 21(10-11): 961-979.

Helfat, C. E., \& Peteraf, M. A. 2003. The dynamic resource based view: capability lifecycles. Strategic Management Journal, 24(10): 997-1010.

Helfat, C. E., \& Campo-Rembado, M. 2010. Integrative capabilities, vertical integration, and innovation over successive technology lifecycles, Tuck School of Business at Dartmouth, Working Paper.

Henkel, J., \& Baldwin, C. Y. 2011. Modularity for Value Appropriation - How to Draw the Boundaries of Intellectual Property. Harvard Business School Working Paper 11-054

Henderson, R. M., \& Clark, K. B. 1990. Architectural innovation: The reconfiguration of existing product technologies and the failure of established firms. Administrative Science Quarterly, 35(1): 9-30.

Jacobides, M. 2005. Industry change through vertical disintegration: how and why markets emerged in mortgage banking. Academy of Management Journal, 48(3): 465-498.

Jacobides, M. G., \& Billinger, S. 2006. Designing the Boundaries of the Firm: From Make, Buy, or Ally to the Dynamic Benefits of Vertical Architecture. Organization Science, 17(2): 249-261.

Jacobides, M. G., \& Winter, S. G. 2005. The co-evolution of capabilities and transaction costs: explaining the institutional structure of production. Strategic Management Journal, 26(5): 395-413.

Kapoor, R. \& Adner, R. 2011. What Firms Make vs. What They Know: How Firms' Product and Knowledge Boundaries Affect Competitive Advantage in the Face of Technological Change. Organization Science.

Klepper, S. 1997. Industry life cycles. Industrial and Corporate Change, 6(1): 145-181.

Lamoreaux, N. R., Raff, D. M. G., \& Temin, P. 2003. Beyond Markets and Hierarchies: Toward a New Synthesis of American Business History. The American Historical Review, 108(2): 404-433.

Langlois, R. 1992. External economies and economic progress: The case of the microcomputer industry. The Business History Review, 66(1): 1-50.

Langlois, R. N., \& Robertson, P. L. 1995. Firms, market and Economic Change: A Dynamic Theory of Business Institutions. London: Routledge.

Langlois, R., \& Robertson, P. 1992. Networks and innovation in a modular system: Lessons from the microcomputer and stereo component industries. Research Policy, 21(4): 297-313.

Langlois, R. N. 2003. The vanishing hand: the changing dynamics of industrial capitalism. Industrial \& Corporate Change, 12(2): 351-385.

Luo, J., Whitney, D.E., Baldwin, C. Y., \& Magee, C. L. 2011. How Firm Strategies Influence the Architecture of Transaction Networks. Harvard Business School Working Paper 11-076

Macher, J. T., \& Mowery, D. C. 2004. Vertical specialization and industry structure in high technology industries. In A. M. McGahan, \& J. A. C. Baum (Eds.), Business Strategy Over the Industry Life Cycle - Advances in Strategic Management. Vol. 21: 317-355. Oxford: Elsevier/JAI Press.

Macher, J. T., Mowery, D. C., \& Hodges, D. 1998. Back to Dominance? US resurgence in the global semiconductor industry. California Management Review, 41(1): 107-136.

Monteverde, K. 1995. Technical Dialog As an Incentive for Vertical Integration in the Semiconductor Industry. Management Science, 41(10): 1624-1638.

Morrison, G. 1998. IBM Flexes Foundry Muscle. Electronic News 44(2210) 1-2.

Mowery, D. C., \& Rosenberg, N. 1982. The commercial aircraft industry. Government and Technological Progress, Pergamon Press, New York.

Parmigiani, A. 2007. Why do firms both make and buy? An investigation of concurrent sourcing. Strategic Management Journal, 28(3): 285-311. 
Porter, M.E. 2008. The five competitive forces that shape strategy. Harvard Business Review, 86(1): 7893.

Qian, L., Agarwal, R., \& Hoetker, G. 2011. Configuration of Value Chain Activities: The Effect of PreEntry Capabilities, Transaction Hazard and Industry Evolution on the Decision to Internalize, Organization Science.

Rosenberg, N. 1963. Technological change in the machine tool industry, 1840-1910. Journal of Economic History, 23(4): 414-443.

Schilling, M. A. 2000. Toward a General Modular Systems Theory and Its Application to Interfirm Product Modularity. Academy of Management Review, 25(2): 312-334.

Smith, A. 1776. An inquiry into the nature and causes of the wealth of nations. Indianapolis, IN: Liberty Classics.

Steinmueller, W. E. 1996. The U.S. Software Industry: An Analysis and Interpretative History. In D. C. Mowery (Ed.), The International Computer Software Industry: 15-52. Oxford: Oxford University Press.

Stigler, G. J. 1951. The division of labor is limited by the extent of the market. Journal of Political Economy, 59: 185-193.

Strojvas, M. 2005. An empirical study of vertical integration in the semiconductor industry. Unpublished Ph.D. dissertation. Harvard University.

Teece, D. J. 1988. Technological Change and the Nature of the Firm. In G. Dosi, C. Freeman, R. Nelson, G. Silverberg, \& L. Soete (Eds.), Technical Change and Economic Theory: 256-281. New York, NY: Pinter Publishing Ltd.

Teece, D. J. 1996. Firm Organization, Industrial Structure, and Technological Innovation. Journal of Economic Behavior and Organization, 31: 193 - 224.

Teece, D. J., Pisano, G., \& Shuen, A. 1997. Dynamic capabilities and strategic management. Strategic Management Journal, 18(7): 509-533.

Williamson, O. E. 1985. The economic institutions of capitalism: firms, markets, relational contracting. New York, London: Free Press, Collier Macmillan.

Wolter, C., \& Veloso, F. M. 2008. The Effects of Innovation on Vertical Structure: Perspectives on Transaction Costs and Competences. Academy of Management Review, 33(3): 586-605.

Yayavaram, S., \& Ahuja, G. 2008. Decomposability in knowledge structures and its impact on the usefulness of inventions and knowledge-base malleability. Administrative Science Quarterly, 53(2): 333-362.

Ziedonis, R. H. 2004. Don't Fence Me In: Fragmented Markets for Technology and the Patent Acquisition Strategies of Firms. Management Science, 50(6): 804-820. 
Figure 1: Number of Fabless (specialized) and IDM (integrated) firms in the semiconductor industry*

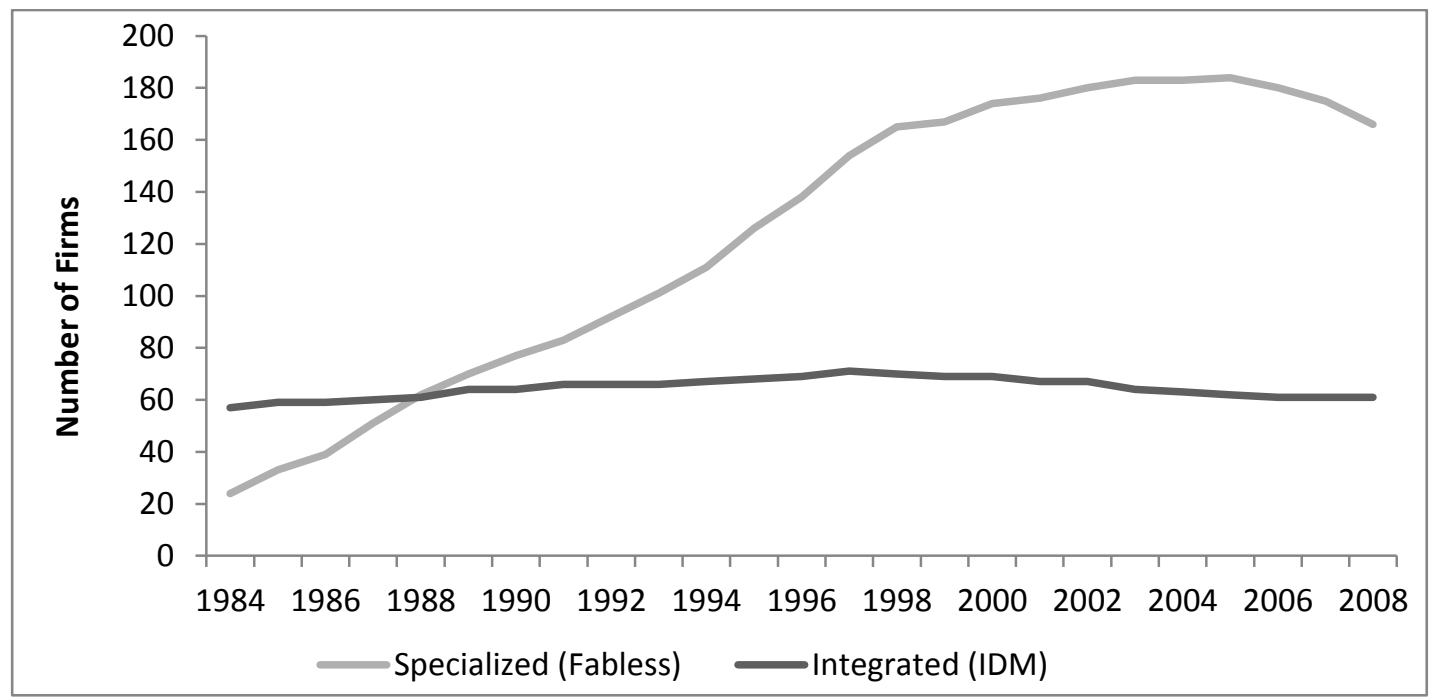

* Data does not include many small privately held fabless start-ups that account for less than $1 \%$ of industry sales

Figure 2: Percentage of patents for IDM and fabless firms that correspond to autonomous and systemic innovations

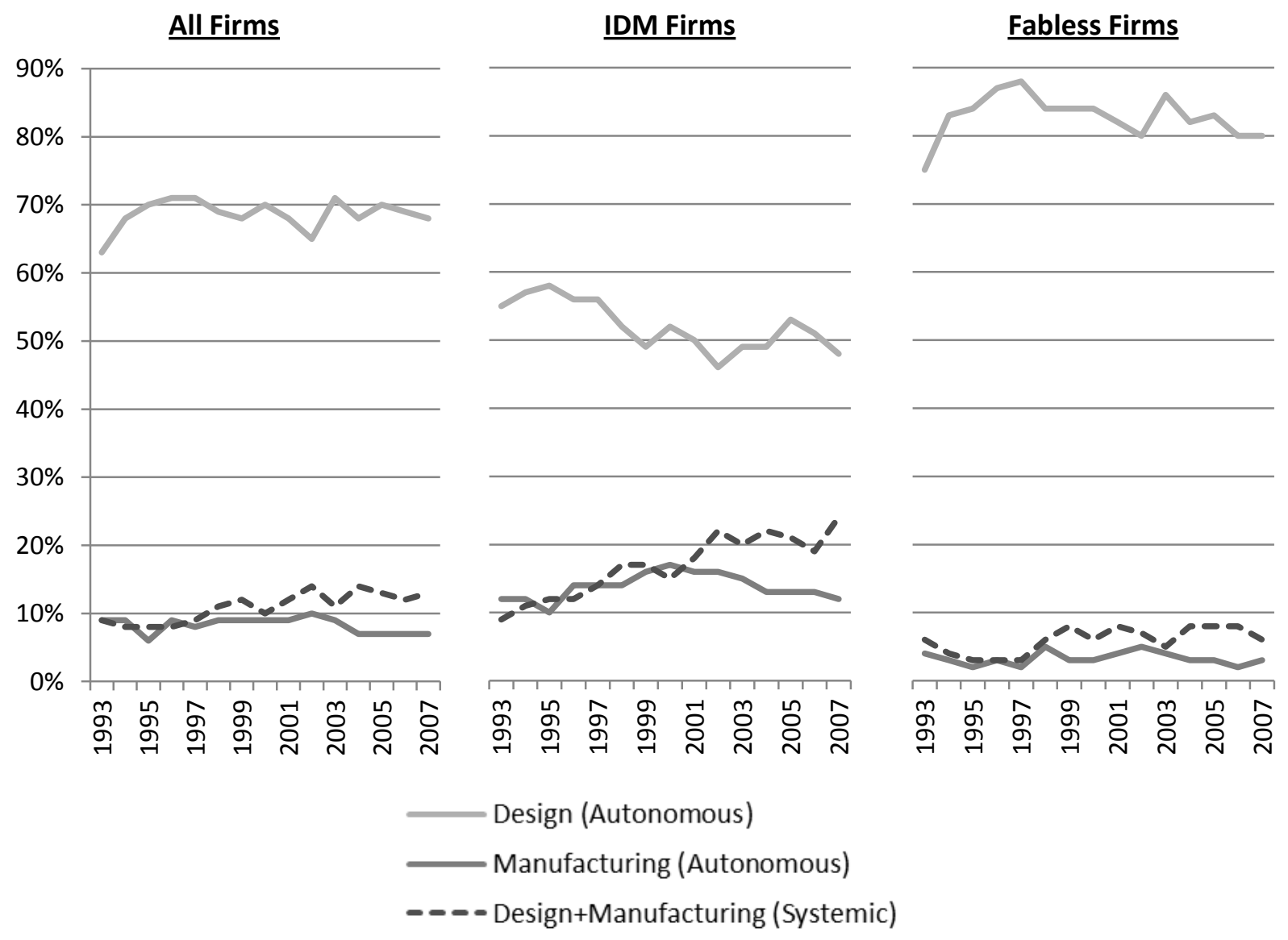


Figure 3. Estimated coefficients and $95 \%$ confidence intervals for the yearly effect on the share of firms' patents corresponding to systemic innovations as reported in Table 3
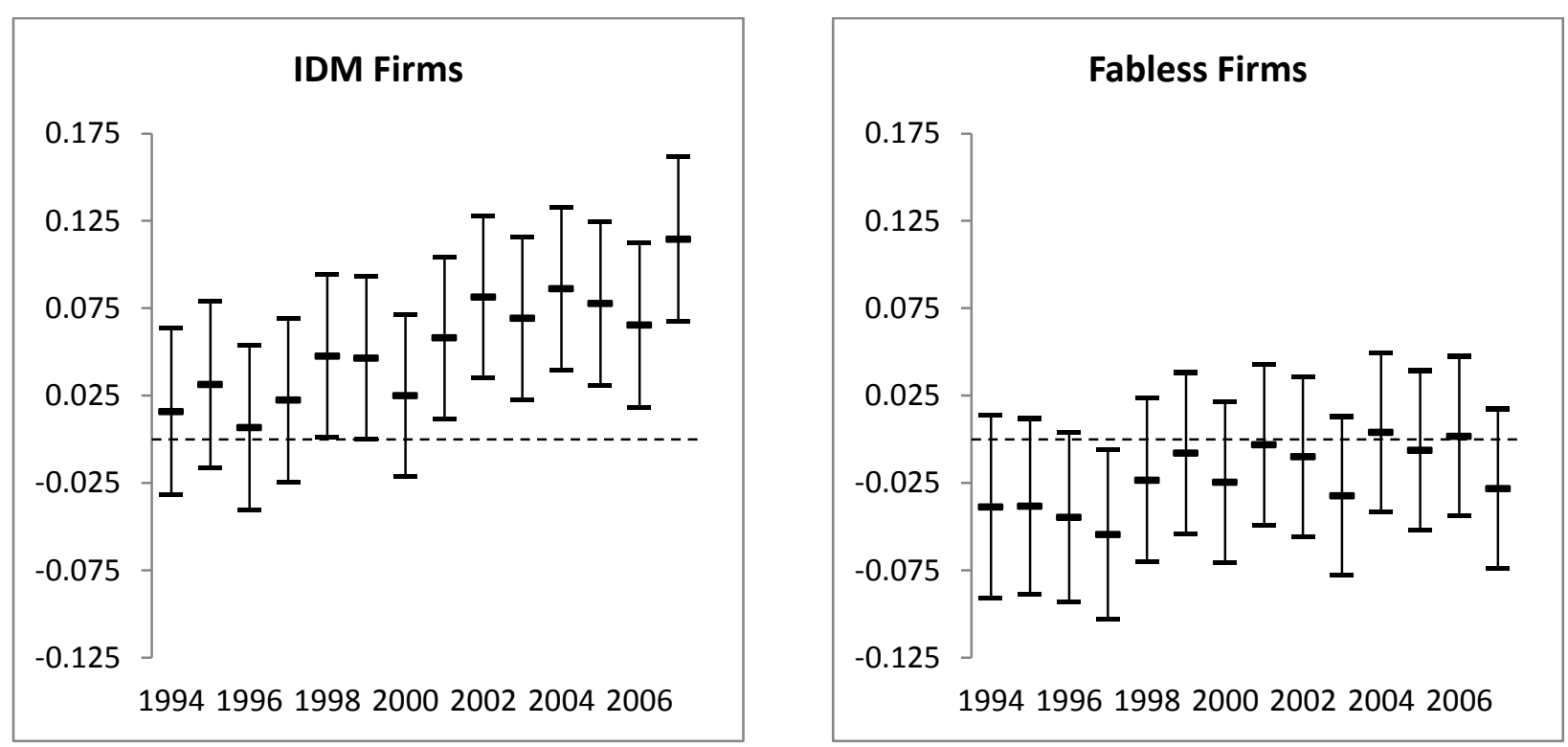

Figure 4: Number of IDM Firms using and offering manufacturing services

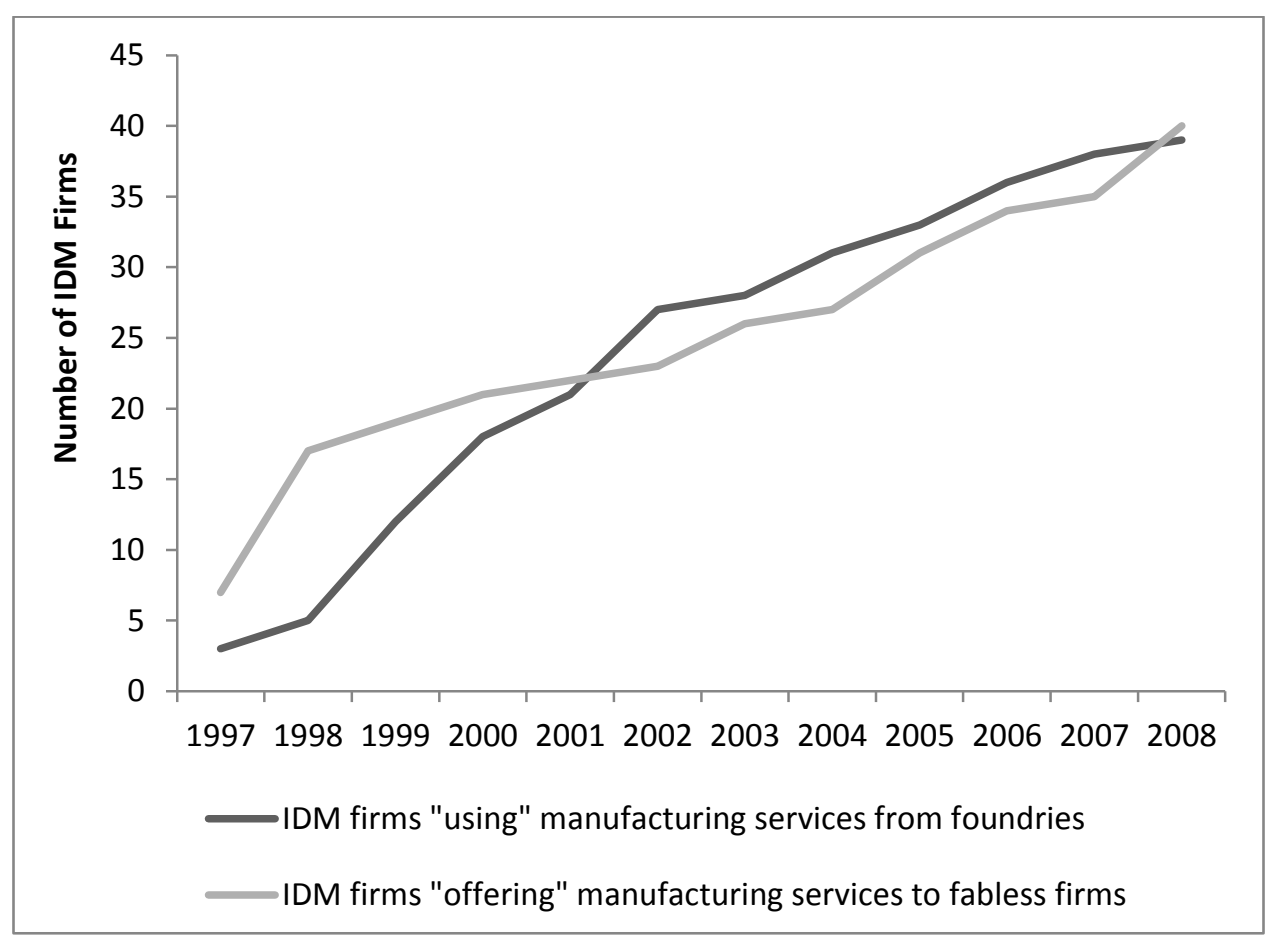


Figure 5: Sales Trend for TSMC and UMC, the two largest foundries (specialized manufacturing firms) in the semiconductor industry

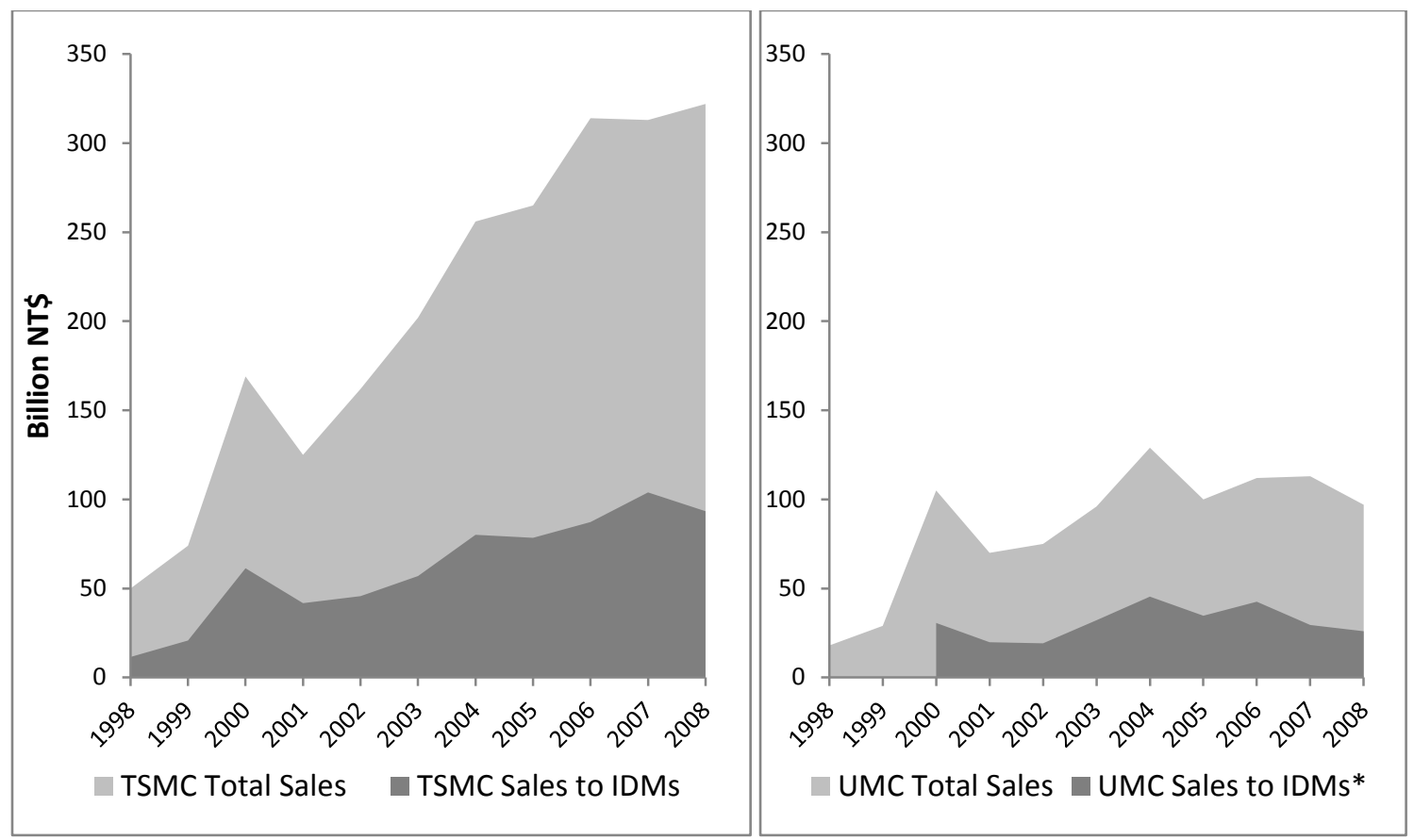

* UMC did not report its sales to IDMs for the years 1998 and 1999.

Figure 6: Evolution of the Semiconductor Industry

Pre-1980

Integrated Firms (IDMs)

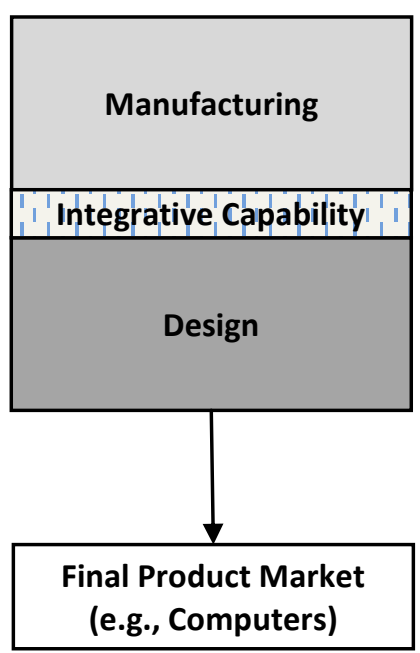

Post-2000

Integrated Firms (IDMs)

Specialized Firms

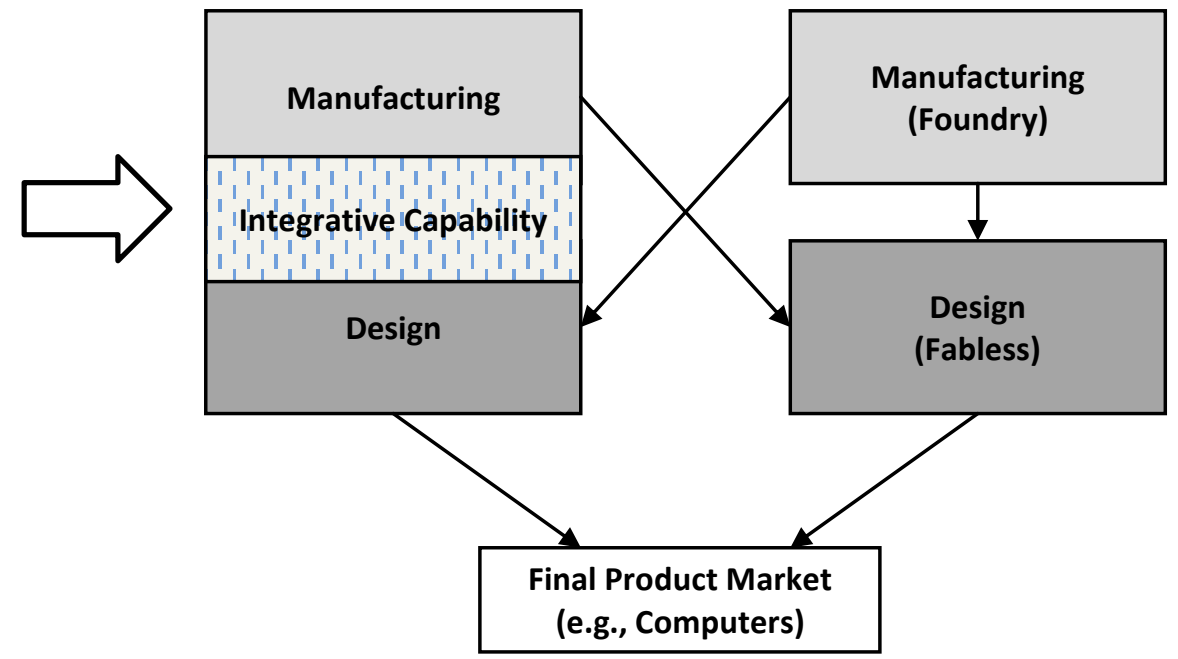


Table 1: OLS estimates for firms' annual Return on Invested Capital (ROIC) for the years 1993-2007

\begin{tabular}{|l|l|}
\hline \multicolumn{2}{|c|}{ Dependent Variable = Return on Invested Capital (ROIC) } \\
\hline Fabless (vs. IDM) & 0.007 \\
\hline & $(0.066)$ \\
\hline Firm Size (Log(Sales in US\$) & $0.080^{* *}$ \\
\hline & $(0.033)$ \\
\hline Firm Age & $-0.003^{*}$ \\
\hline & $(0.002)$ \\
\hline Conglomerate & -0.133 \\
\hline & $(0.088)$ \\
\hline Industry Revenue & -0.001 \\
\hline & $(0.001)$ \\
\hline Industry Revenue Growth & $0.208 * *$ \\
\hline & $(0.100)$ \\
\hline Japanese Firm & 0.024 \\
\hline & $(0.102)$ \\
\hline Taiwanese Firm & $0.227 * * *$ \\
\hline & $(0.076)$ \\
\hline American Firm & 0.078 \\
\hline & $(0.091)$ \\
\hline Constant & -0.313 \\
\hline & $(0.227)$ \\
\hline Observations (Firm-Year) & 2276 \\
\hline R-squared & 0.02 \\
\hline
\end{tabular}

Robust standard errors in parentheses, clustered by firm.

$*$ significant at $10 \%$;* significant at $5 \% ; * * *$ significant at $1 \%$ 
Table 2: Classification of Derwent classes into design or manufacturing ${ }^{\mathrm{a}}$

\begin{tabular}{|c|c|c|c|c|}
\hline $\begin{array}{l}\text { Derwent } \\
\text { Section }\end{array}$ & $\begin{array}{l}\text { Derwent } \\
\text { Class }\end{array}$ & Derwent Section Title & Derwent Class Title & Class Type \\
\hline $\mathrm{L}$ & L03 & Glass, Ceramics, Electro(In)organics & Electro(In)Organics & Semiconductor Manufacturing \\
\hline $\mathrm{L}$ & L04* & Glass, Ceramics, Electro(In)organics & Semiconductors & Semiconductor Manufacturing \\
\hline $\mathrm{U}$ & $\mathrm{U} 11 *$ & Semiconductors and Electronic Circuitry & Semiconductor Materials and Processes & Semiconductor Manufacturing \\
\hline $\mathrm{U}$ & U12 & Semiconductors and Electronic Circuitry & Discrete Devices & Circuit Design \\
\hline $\mathrm{U}$ & U13 & Semiconductors and Electronic Circuitry & Integrated Circuits & Circuit Design \\
\hline $\mathrm{U}$ & $\mathrm{U} 14^{*}$ & Semiconductors and Electronic Circuitry & Memories, Film and Hybrid Circuits & Circuit Design \\
\hline $\mathrm{U}$ & $\mathrm{U} 21 *$ & Semiconductors and Electronic Circuitry & Logic Circuits, Electronic Switching and Coding & Circuit Design \\
\hline $\mathrm{U}$ & $\mathrm{U} 22$ & Semiconductors and Electronic Circuitry & Pulse Generation and Manipulation & Circuit Design \\
\hline $\mathrm{U}$ & $\mathrm{U} 23$ & Semiconductors and Electronic Circuitry & Oscillation and Modulation & Circuit Design \\
\hline $\mathrm{U}$ & $\mathrm{U} 24$ & Semiconductors and Electronic Circuitry & Amplifiers and Low Power Supplies & Circuit Design \\
\hline $\mathrm{U}$ & $\mathrm{U} 25$ & Semiconductors and Electronic Circuitry & Impedance Networks and Tuning & Circuit Design \\
\hline $\mathrm{W}$ & W01* & Communications & Telephone and Data Transmission Systems & Application Specific/System Design \\
\hline $\mathrm{W}$ & $\mathrm{W} 02 *$ & Communications & Broadcasting, Radio and Line Transmission & Application Specific/System Design \\
\hline $\mathrm{W}$ & W03 & Communications & TV and Broadcast Radio Receivers & Application Specific/System Design \\
\hline $\mathrm{W}$ & W04* & Communications & Audio/Video Recording and Systems & Application Specific/System Design \\
\hline $\mathrm{W}$ & W05 & Communications & Alarm, Signalling, Telemetry and Telecontrol & Application Specific/System Design \\
\hline $\mathrm{W}$ & W06 & Communications & Aviation, Marine and Radar Systems & Application Specific/System Design \\
\hline $\mathrm{W}$ & W07 & Communications & Electrical Military Equipment and Weapons & Application Specific/System Design \\
\hline $\mathrm{T}$ & $\mathrm{T} 01 *$ & Computing and Control & Digital Computers & Application Specific/System Design \\
\hline $\mathrm{T}$ & T02 & Computing and Control & Analogue and Hybrid Computers & Application Specific/System Design \\
\hline $\mathrm{T}$ & $\mathrm{T} 03$ & Computing and Control & Data Recording & Application Specific/System Design \\
\hline $\mathrm{T}$ & T04 & Computing and Control & Computer Peripheral Equipment & Application Specific/System Design \\
\hline $\mathrm{T}$ & T05 & Computing and Control & Counting, Checking, Vending, ATM \& POS & Application Specific/System Design \\
\hline $\mathrm{T}$ & T06 & Computing and Control & Process and Machine Control & Application Specific/System Design \\
\hline $\mathrm{T}$ & T07 & Computing and Control & Traffic Control Systems & Application Specific/System Design \\
\hline
\end{tabular}

* major classes that account for at least $5 \%$ of all patents for IDM or fabless firms

${ }^{a}$ one expert commented that class U14 may also correspond to manufacturing. As a robustness check, I excluded all patents that were classified in this class and the observed pattern was very similar to the one reported in the main results. 
Table 3: Fixed effects estimates for the share of firms' patents corresponding to systemic innovations. $^{\text {a }}$

\begin{tabular}{|c|c|c|}
\hline & (1) & (2) \\
\hline & $\mathrm{IDM}^{\mathrm{a}}$ & Fabless \\
\hline \multirow[t]{2}{*}{ Semiconductor patent ratio } & $0.166 * * *$ & $0.076 * * *$ \\
\hline & $(0.029)$ & $(0.024)$ \\
\hline \multirow[t]{2}{*}{1994} & 0.016 & -0.039 \\
\hline & $(0.024)$ & $(0.027)$ \\
\hline \multirow[t]{2}{*}{1995} & 0.031 & -0.038 \\
\hline & $(0.024)$ & $(0.026)$ \\
\hline \multirow[t]{2}{*}{1996} & 0.007 & $-0.045^{*}$ \\
\hline & $(0.024)$ & $(0.025)$ \\
\hline \multirow{2}{*}{1997} & 0.022 & $-0.055^{* *}$ \\
\hline & $(0.024)$ & $(0.025)$ \\
\hline \multirow[t]{2}{*}{1998} & $0.047 * *$ & -0.023 \\
\hline & $(0.024)$ & $(0.024)$ \\
\hline \multirow[t]{2}{*}{1999} & $0.047 *$ & -0.008 \\
\hline & $(0.024)$ & $(0.024)$ \\
\hline \multirow[t]{2}{*}{2000} & 0.025 & -0.025 \\
\hline & $(0.024)$ & $(0.024)$ \\
\hline \multirow[t]{2}{*}{2001} & $0.058^{* * *}$ & -0.003 \\
\hline & $(0.024)$ & $(0.023)$ \\
\hline \multirow[t]{2}{*}{2002} & $0.081^{* * * *}$ & -0.010 \\
\hline & $(0.024)$ & $(0.023)$ \\
\hline \multirow[t]{2}{*}{2003} & $0.069 * * *$ & -0.032 \\
\hline & $(0.024)$ & $(0.023)$ \\
\hline \multirow[t]{2}{*}{2004} & $0.086 * * *$ & 0.004 \\
\hline & $(0.024)$ & $(0.023)$ \\
\hline \multirow[t]{2}{*}{2005} & $0.078 * * *$ & -0.006 \\
\hline & $(0.024)$ & $(0.023)$ \\
\hline \multirow[t]{2}{*}{2006} & $0.065 * * *$ & 0.002 \\
\hline & $(0.024)$ & $(0.023)$ \\
\hline \multirow[t]{2}{*}{2007} & $0.115 * * *$ & -0.028 \\
\hline & $(0.024)$ & $(0.023)$ \\
\hline \multirow[t]{2}{*}{ Constant } & -0.018 & 0.011 \\
\hline & $(0.029)$ & $(0.030)$ \\
\hline Number of Observations & 1576 & 1840 \\
\hline Number of Firms & 158 & 236 \\
\hline R-squared (between) & 0.26 & 0.01 \\
\hline R-squared (within) & 0.06 & 0.02 \\
\hline
\end{tabular}

Standard errors in parentheses

* significant at $10 \%$; ** significant at 5\%; *** significant at $1 \%$

a The data includes both publicly listed and private IDM firms that are listed in SEMI's world fab watch database

Year 1993 is the omitted year dummy 